\title{
Roasted instant coffees: analysis of (poly)phenols and melanoidins antioxidant capacity, potassium and sodium contents
}

\author{
S.A. Palma-Duran, M.E.J. Lean and E. Combet \\ Human Nutrition, School of Medicine, University of Glasgow, G31 2ER, UK
}

Chlorogenic acids (CGA) are one of the main polyphenol groups in the diet, found especially in coffee, tea, stone fruits (peaches and plums) and some vegetables (artichoke, chicory). CGA levels in coffee depend on roasting times and temperature. The roasting process promotes the incorporation of GCA into melanoidins; a Maillard reaction product (MRP) that contributes to the antiglycative, anti-inflamatory and antioxidant properties of coffee ${ }^{(1)}$. Despite these potential health benefits, coffee is sometimes restricted for its high potassium content in the context of renal impairment. Therefore, we analysed the antioxidant capacity of (poly)phenols and melanoidins of dark roasted instant coffee, and the antioxidant contribution of (poly)phenols non-covalently-linked to melanoidins after gastrointestinal digestion stimulation. Additionally, potassium and sodium were evaluated.

Instant roasted coffees $(n=20)$ were selected from local supermarkets. Coffee $(1.8 \mathrm{~g})$ was brewed in $200 \mathrm{~mL}$ boiling water $\left(100^{\circ} \mathrm{C}\right)$ and paper-filtered. Brewed coffee was ultra-filtrated (10 kDa cutoff filter), digested in vitro and re-ultrafiltrated. From this, four fractions were obtained: i) brewed coffee (BC), ii) ultra-filtrated coffee (FC), iii) digested melanoidins (DM), and iv) digested ultra-filtrated melanoidins (DFM). Melanoidins analysis was done as an indirect parameter of their intermediate $(360 \mathrm{~nm})$ and final $(420 \mathrm{~nm}) \mathrm{MRP}$ content $^{(2)}$. Antioxidant capacity was analyzed by total phenols, flavonoids and FRAP.

\begin{tabular}{|c|c|c|c|c|c|c|c|c|c|c|}
\hline \multirow[b]{3}{*}{ Coffee fractions } & \multicolumn{4}{|c|}{ Melanoidins } & \multirow{2}{*}{\multicolumn{2}{|c|}{ Total phenols }} & \multirow{2}{*}{\multicolumn{2}{|c|}{ Total flavonoids }} & \multirow{2}{*}{\multicolumn{2}{|c|}{ FRAP }} \\
\hline & \multicolumn{2}{|c|}{$360 \mathrm{~nm}$} & \multicolumn{2}{|c|}{$420 \mathrm{~nm}$} & & & & & & \\
\hline & Mean & SD & Mean & SD & Mean & SD & Mean & SD & Mean & SD \\
\hline Brewed coffee (BC) & 1.52 & $0 \cdot 17$ & 0.45 & 0.09 & 69.65 & 8.98 & 11.71 & 1.23 & 129.94 & $11 \cdot 9$ \\
\hline Ultra-filtrate coffee (FC) & 0.69 & $0 \cdot 10$ & 0.17 & 0.02 & 30.50 & 5.58 & 5.71 & 1.05 & 69.46 & 8.74 \\
\hline Digested melanoidins (DM) & 0.60 & 0.28 & 0.30 & $0 \cdot 16$ & $12 \cdot 84$ & 2.91 & 6.61 & 2.02 & 11.03 & 2.95 \\
\hline Digested ultra-filtrated melanoidins (DFM) & 0.35 & 0.21 & 0.13 & 0.07 & 4.77 & $3 \cdot 61$ & 3.65 & 3.38 & 4.76 & 3.42 \\
\hline
\end{tabular}

Melanoidins are expressed in absorbance units. Total phenols, total flavonoid and ferric reducing activity are expressed as $\mathrm{mg} / \mathrm{g}$ of gallic acid, $\mathrm{mg} / \mathrm{g}$ of quercetin and $\mathrm{mg} / \mathrm{g} \mathrm{Fe}^{2+} / \mathrm{g}$ equivalents respectively.

The DM fraction presented a higher absorbance of final MRP than intermediate MRP, considering the absorbance of BC. The FC had a higher antioxidant contribution to the overall antioxidant capacity of the coffee than the DCC \& DFC fractions. The great variability of absorbance and antioxidant capacity in the DM and DFM may be due to the raw coffee composition. Although the (poly)phenol content depends not only on the roasting process, both (poly)phenols and melanoidins contributes to the antioxidant capacity of coffee. The reduction of the (poly)phenols is balanced by their incorporation into coffee melanodins.

Instant coffees contained $1.55(0.04)$ mmol of potassium and $0.14(0.01)$ mmol of sodium per cup. In a regular coffee drinker, an intake of 3-4 cups/day of coffee have been associated with a reduced risk of stroke of $17 \%$ and $25 \%$ lower risk of diabetes type 2 . This levels of intake represents $7 \cdot 0-10 \%$ of potassium intake in adults $(50-150 \mathrm{mmol} /$ day $)$ or $10-13 \%$ intake of potassium-restricted diet $(30-60 \mathrm{mmol} / \mathrm{day})^{(3)}$. Therefore, potassium and sodium content in coffee does not represent a risk in mild renal failure, where coffee and tea are not absolutely prohibited.

S.P acknowledges PhD CONACyT scholarship and Michael Beglan for potassium \& sodium analysis.

1. Ludwig IA, Clifford MN, Lean ME, et al. (2014). Food \& function. 5, 1695-1717.

2. Delgado-Andrade C, Morales FJ, Seiquer I, et al. (2010). Food research international. 43, 1304-1311.

3. Turner N, Adlakha A, Gibson P. Edren Textbook. Edinburgh 2003. 